\title{
Politics and the 'Ideology' of Journalism in Romania: Results from Local Case Studies
}

\author{
Cristina Stănuş ${ }^{2}$ *
}

${ }^{1}$ Babeş-Bolyai University of Cluj-Napoca, Department of Sociology, 12821 Decembrie 1989 Bld., 400604 Cluj-Napoca, Romania

${ }^{2}$ Lucian Blaga University of Sibiu, Chair of Political Science, 34 Calea Dumbrăvii, 550324 Sibiu, Romania

KEYWORDS

Journalism

Local news media

Politics

Professionalization

Romania

\section{A BSTRACT}

The paper approaches the 'ideology' of Romanian postcommunist journalism as identified in local news media organisations. We focus on the practical philosophy of journalism, emphasizing elements such as autonomy, truth, objectivity; and the relationship of journalists and news organisations with political actors. Special attention is given to the interplay between this practical philosophy and the political and economic constraints influencing news media organisations in Romania. We approach this topic using in-depth interviews with journalists and editors from news media organisations in three Romanian cities. We argue that two different 'ideologies' of journalism as a profession exist. These are complemented by a tendency toward reducing journalism to a simple occupation, linked to the politicization of media ownership in Romania and the widespread use of media organisations as vehicles for the free speech of their owners.

\section{Introduction}

Freedom of expression and media freedom are often justified from an instrumental point of view, placing a strong emphasis on their role in seeking the truth, ensuring individual autonomy, the rise and endurance of democratic government, and in controlling the activity of government (Barendt 2007). From the discussion on the importance of the freedom of expression and media freedom in the emergence and survival of Western

\footnotetext{
*Contact address: cristina.stanus@ulbsibiu.ro (C. Stănuş)
} 
democracies derives an equally important discussion on the importance of these two elements during democratic transition and consolidation. Translating the free speech principle in the political systems of the new democracies (or creating a local variation of the liberal free speech system) is usually equalled with removing the media control mechanisms of the previous regime, introducing constitutional guarantees for freedom of expression and media freedom, and less intrusive media policy. Beyond these aspects, the democratisation of public communication also involves an institutional reorganisation of existing media organisations, the introduction of a new definition of the journalist's role in society, as well as new quality standards in the process of news gathering and dissemination (Voltmer 2000). The latter aspect is particularly relevant given that journalism usually overshadows other means of free speech.

All discussions of media freedom unavoidably involve two divergent positions and special attention to matters of limitations and constraints. On the one hand, we have people who argue that there should be no limits and constraints to media freedom. On the other hand, we have theorists and practitioners who believe that the free speech of individuals and media organisations should be balanced with a society's needs and interests; and, if needs and interests require it, limitations and constraints may exist. Views on free speech, media freedom and mass media's role in a democratic regime find their reflection within the media system, in the practical philosophy that underpins journalism and day-to-day practices within contemporary media organisations. This paper approaches, in an analysis of Romanian post-communist media organisations, dominant views on journalism as a profession and on the interactions between media organisations, political actors, and media owners. After a brief review of literature we detail the research methodology. Next, we focus on the professionalization of journalism in post-communist Romania and on what we might label 'the ideology' of journalism, the set of values, norms, and behaviours defining the profession. Later on, we emphasize the place of free speech within this ideology, as well as the manner in which the tripartite relationship between journalists, media owners and political actors is defined. 


\section{Media freedom and the professionalization of journalism}

Any discussion on media freedom in a democratic regime involves philosophical (meaning of free speech and its justifications), constitutional, administrative, political, and economic aspects. The link between the former and the latter categories is not explicit, but it becomes obvious if we frame the issue in terms of comparing media systems. Free speech as a fundamental principle of modern liberal democracies is translated into practice in a variety of institutional contexts, shaped by the political economy of media organisations. Typically, media organisations have mixed goals, deriving from their economic nature and the role attributed to them within society and the political system. What differentiates media systems is the manner in which these goals interact with each other and influence the interactions of media organisations with other social and political actors. This dual character of media organisations is reflected in four dimensions used to compare media systems: the development of the media market, political parallelism, the professionalization of journalism, and the nature and degree of state intervention in the media system (Hallin and Mancini 2004). Among these, the professionalization of journalism is highly relevant for the accommodation of the mixed goals of media organisations.

Ideally and similarly to other liberal professions, the professionalization of journalism would involve practising journalism based on systematic knowledge acquired through prescribed professional training, professional authority, the recognition of the profession as such by the community, ethics codes to regulate day-to-day activity, and a specific culture (Tumber 2006). The professionalization of journalism along these criteria seems quite impossible. Consequently, Hallin and Mancini (2004) propose three dimensions of professionalization, specific to journalism, as an alternative to the classical criteria: professional autonomy, the existence of distinct professional norms, and a public service orientation. The three criteria correspond to the evaluative, normative, and cognitive dimensions of a profession (see Singer 2003). In this sense, the professionalization of journalism refers to the internalization of professional norms and values such as objectivity, autonomy (controlling access to the profession, ethics codes, specialised skills and knowledge), and public service orientation by journalists and media organisations; and to embedding these norms and 
values in day-to-day operations (Broddason 1994; Hallin and Mancini 2004). Autonomy is lower when compared to other liberal professions, due to the lack of esoteric knowledge specific to the other professions, fact partially compensated by the collegial control process (Hallin and Mancini 2004). Some authors suggest that, even though journalism fails to meet all the criteria we usually find in a sociological definition of a profession, the sacred side of journalism deriving from the idea of service to society and to democracy is enough to compensate and grant journalism its status as profession (Broddason 1994). In this line of thought, self-identification with journalism as a profession may be entirely based on subjective elements rather than objective elements such as rules and regulations.

The professionalization of journalism is often associated with an 'ideology' of journalism, i.e. the system of values centred on truth and objectivity guiding the profession. As in the case of other professions, the ultimate value -in the case, the truth - is a general social value. Deriving from this, in a philosophical perspective, the practice of journalism involves finding answers to questions such as the meaning and operationalization of objectivity; morality, competence and defining good journalism; determining newsworthiness and the protection of the private sphere (Cohen 1992). In day-to-day journalistic practice we will not find the concepts and theories underpinning these aspects, however we will find a 'professional imaginary' helping journalists to differentiate themselves from their sources and audiences and giving them a sense of legitimacy (Heikkilä and Kunelius 2006). Traditionally, this professional imaginary locates the journalists' activities at national level, frames the news using the notion of common good as a frame, and positions the journalist as detached observer, neutral mediator and critical commenter (Heikkilä and Kunelius 2006). This classical notion of professionalism is still dominant, but there is a trend towards replacing it under the influence of the convergence and Europeanization processes. The emergence of new media and convergence bring about two important changes for journalism: first, the proliferation of information sources challenges the role of the journalist as an 'expert' in information dissemination, and second, a change of journalistic culture that can be labelled de-professionalization (Tumber 2006) 
In the literature we find divergent opinions on the degree of convergence in terms of values associated with professionalization. Some authors claim similarities exist beyond national political cultures and contexts (Deuze 2005), or go as far as using these values and the notion of professionalization as a key criterion in comparing media systems (Blumler and Gurevitch 1995; Hallin and Mancini 2004). Other authors find diversity in how the professional roles, values and standards of journalism are defined (Kepplinger and Köcher 1990; Köcher 1986), or emphasize the need to investigate journalism as a profession within the limits of specific media systems (Ruusunoksa 2006). Research on the professional self-image of Eastern European journalism shows clear differences in terms of norms and values when compared to their Western European counterparts (Voltmer 2000). These differences stem from different views of media freedom, as a fundamental and founding concept of the professional activity of journalists. A frequent example is the unique distinction between the internal and external freedom of the media present in the German constitution (see Kepplinger and Köcher 1990). In Germany, internal media freedom refers to the independence of journalists from the owners of the media organisations, while external media freedom refers to the independence of media organisations from the state (Kepplinger and Köcher 1990). Another important aspect is a challenge to the traditional notion of journalism as a profession, which comes with the notion of on-line journalism (Singer 2003).

A defining feature of all media systems, usually in opposition with the professionalization of journalism, is the instrumentalisation of media organisations by actors (political parties, politicians, social groups or movements) from outside the media system (Hallin and Mancini 2004: 37). The literature sometimes describes this phenomenon using the notion of political control, which involves the use of legal, normative, structural, and economic instruments (Graber 1997). Among these, normative control involves a set of rights and duties determined by the expectation of benefits for both individuals and society, built upon the theory and practice of journalism, the opinions of the citizens, and the views of the state and of other stakeholders in society (see McQuail 2010: 162-163). Normative control is deeply linked with the idea that media organisations should be governed by the same democratic principles as the political system and the rest of the 
society. The extent to which this set of expectations favours pluralism and free speech as opposed to media's role in supporting the political regime depends on the political culture. Hallin and Mancini (2004: 37) find a reverse proportion relationship between the professionalization of journalism and the instrumentalisation of media organisations by their owners or certain political actors.

Using these findings as starting point, one research question we intend to answer is how professionalization is defined by the journalists, editors, and managers in Romanian media organisations. Specifically, we aim to identify the values that fundament this definition; the meanings attributed to concepts such as objectivity, autonomy, and public service; the social and political role of Romanian media as seen from within the media system; and the extent to which the professionalization of journalism is based on clear concepts, rules, and procedures, as opposed to symbolic elements. A second research question aims to map instrumentalisation in the Romanian media system and its potential links with the professionalization of journalism.

\section{Method and data}

We approach these research questions focusing on local media organisations. The first reason behind our choice is the widespread opinion that local media organisations in Romania are controlled (read 'owned indirectly') by local politicians and business men, who use them to further personal, political or business goals. A second reason is linked to the economic vulnerability of local media organisations, deriving from the limited market on which they operate (audiences and advertising), which makes them more susceptible to intervention of public authorities (they can buy advertising or choose to ignore the debts a media organisation has). From this perspective, given the differences in terms of operating conditions between national and local news media, we can say we have two parallel media systems in Romania. The focus on local media organisations provides us with the opportunity to explore in-depth sensitive topics related to the relationships between media organisations, journalists, and political actors. At the same time, taking into account empirical results from other national contexts which suggest that this profession is defined differently at the 
various levels the media organisations operate (local, regional, national; see Ruusunoksa 2006), it has the disadvantage of giving us a partial image of how this profession is defined in Romania.

The analysis comprises three case studies, focused on local news media in the cities of Braşov, Iaşi and Timişoara. These cases were selected taking into account the following criteria: the size and degree of diversification of the local media market and whether or not we can indentify open conflicts between journalists and local political actors or instances of soft censorship by the local public authorities (such as refusing access to information for certain journalists).

The case studies are built upon a series of in-depth interviews with journalists, editors and managers in local news media organisations, as well as upon contextual information. The respondents were selected so as to maximise diversity in terms of professional training (journalism graduates opposed to graduates in other domains), age and experience (journalists working since before 1989 opposed to new recruits), position within the organisation (managers, editors, experienced journalists, beginner journalists), medium (print media, television, radio), and type of media (prestigious vs. popular media, as defined by Kepplinger and Köcher 1990). An overarching criterion in the case of editors and journalists was their area of expertise, namely we selected those in charge of political news. The interview guide focused on political, economic, and organisational aspects of local media organisations; how journalism is defined as a profession; and what are the values which define relationships and practices (free speech, public interest, diversity, and pluralism).

Data analysis showed very little variation between our three cases. The main difference stems from the degree of political involvement of media owners: in Braşov we have media owners which are explicitly and publicly involved with a political party, in Iaşi owners 'are not enlisted but have political sympathies' ${ }^{\prime}$, in Timişoara we have a mixture of explicit and implicit political involvement. At the same time, in Iaşi we have overt political partisanship of certain media organisations, going as far as constantly publishing opinion editorials by certain local politicians.

1 From this point onwards all text marked with " or otherwise emphasized and not accompanied by a reference represents quotes from the interviews. 
Practically, we have a certain degree of media-party parallelism, which cannot be found in the other two cities. While such parallelism is rejected by most of our respondents, we must note that from a citizens' information perspective it can be a good thing. Comparative research results show that politically engaged media offer more critical coverage as opposed to selfdefined autonomous media (Benson and Hallin 2007). Another difference between the three cities stems from the availability of potential respondents to discuss the critical aspects approached by this investigation. In Timişoara all people contacted agreed to the interview and in Iaşi we had only one refusal. In Braşov those contacted seemed to have perceived the potential topics of the interview as much too sensitive, if we take into account that we had many refusals.

\section{The 'ideologies' of journalism in Romania}

The 'ideology' of journalism describes the manner in which journalists attribute meanings to their work, the system of values underpinning journalism (Deuze 2005) and, especially, the beliefs, ideas, and opinions journalists have on their social and political role. This occupational ideology allows journalists to self-legitimise their position in society (Deuze 2005). Among the elements frequently included in this 'ideology', namely public service, objectivity, autonomy and professional ethics, we focus on the notion of public service, trying to determine how Romanian journalists describe their profession from this perspective.

The notion of public service generally includes the social and political role attributed in a given society to media organisations. De facto roles may not coincide with theoretically attributed roles; while many journalists around the world learn in journalism schools the principles associated with American objectivism, they do not necessarily translate in day-to-day journalistic practices and the subjective view journalists and media organisations hold concerning their political role (Algarra and Gaitano 2011).

Looking at the issue of journalists' social and political role, we identify in Romania two very different 'ideologies' of journalism, each involving subjective identification with different aspects of the profession. This is by 
no means specific to Romania. Research in other post-communist states has also pointed out the co-existence of two different sets of professional values, norms and standards, characterising two professional sub-cultures, specific to the generation of journalists active during the antecedent political regime and, respectively, to the newer generation (see Pasti 2005; Voltmer 2000).

The first of these professional sub-cultures sees the journalist in an active-promotional role (see Donsbach and Patterson 2004), and goes even further:

The journalist makes a moral and spiritual purge of society. We ask questions, we criticise if it is the case, we bring into discussion things which are not the way they were supposed to be.

Media power allows the journalist to do these things:

The press can create mentalities, can create currents of thought, can create morality, can educate the audience.

Journalists approach social issues and push ideas. In this view, journalists and media organisations are far more than the upholders of citizens' interests in a democracy. The journalist decides what is moral or immoral in a given society and uses the instruments of the profession to pursue hers or his subjective morality. The journalist decides 'how things are supposed to be' and brings into discussion all things she or he feels are out of place. In this view, on behalf of individuals and the society, the journalist assumes the role of decision-maker on matters of morality, the common good and public interest. Thus, journalists promote their subjective ideas, values and beliefs, but also invoke the notion of objectivity as a standard of their journalistic practices. The contradiction is ostensible, given the multitude of definitions we can give to the notion of journalistic objectivity (see Cohen 1992). We have a self image of the journalist as a public intellectual, very much consistent with the continental tradition of opinion journalists. At the same time, we have a clearly assumed and socially desirable consequentialism of the journalists' work; these journalists clearly state their social responsibility. One aspect that remains unclear is what media accountability mechanisms fit with this 'ideology' of journalism.

The ideas of the newcomers to this profession are in clear contrast with this view. Younger journalists seem to emphasize the role of the journalist as disseminator of information, in a passive-neutral positioning in relation with 
political actors (Donsbach and Patterson 2004). Unclear and denoting less self-reflection, this view sees the journalist as an expert in gathering and disseminating information, with objectivity and axiological neutrality, yet aiming to influence political and policy decision-making through her or his work. Consequentialism is not explicit; it is unclear to what extent these journalists do perceive the consequences, even unintentional, of their work. This 'ideology' of young journalists sees journalism quite explicitly as a public service. The confusion becomes obvious when these journalists are supposed to define public interest. This is a very vague notion; some of the respondents even declared that public interest involves 'giving the audience all the things they are interested in'. It is quite unclear whether public interest is a simple aggregation of individual interests or the result of some kind of societal deliberation process. Vagueness persists in terms of accountability mechanisms: laissez-faire accountability seems the only option, since journalism as a public service is:

(...) part idealism, part profit-making. If you want profit people must buy you (...). The audience is more specialised, they learned something in the past sixteen years, if you do not provide quality they will not buy.

A tension is pointed out between this view and the view of older journalists, newcomers frequently stating that they are unable to translate into practice the values and beliefs they brought with them when entering this profession.

A completely different view is specific to a third category of journalists, whose numbers are constantly growing. These are the bureaucrat-journalists, who do not identify subjectively with journalism and never did. They practice journalism as an occupation, in a passivepromotional manner (see Donsbach and Patterson 2004). In their day-to-day activity they only approach non-controversial topics and they tend to reproduce uncritically information received from official sources. In principle, this is a self-preservation and self-defence mechanism (see also Bot 2004):

(...) the journalists with sleeve protectors, as I call them, or bureaucratjournalists. Some of them entered the press believing they will find a lot of money. In expectation of a better job they remain in the press, put on their sleeve protectors and write everything told during a press conference or nicely put down on paper everything their editor dictates. 
This last category of journalists tends to minimise the meaning of the public service provided by the mass media, as they put an equal sign between public service and 'cases in which we actually help people'. Media's service does not refer to the society as a whole or the political system. It refers to a media acting as spokespersons for the weak and needy, getting involved in collecting funds for various causes, or the lobby the local correspondent of a national newspaper feels he can do in favour of a much needed highway.

\section{Journalism in Romania: the mirage of a profession}

The professionalization of journalism in Romania can be approached from three different perspectives: with reference to the sociological criteria for defining a profession, with reference to elements of subjective identification with journalism as a profession, or with reference to a combination of the two. We employ the third perspective to discuss along which criteria has journalism professionalised in Romania.

Journalism is often a transitional job for the recruits that either fail or do not wish to adapt to the news-gathering routines imposed by the constraints under which local news media in Romania operate. Some recruits explicitly mention the practice of 'getting the news at all costs', meaning that media organisations encourage journalists to break some professional norms and standards so that costs are reduced and some competitive advantage is gained. On the other side, editors and managers admit some 'commuters' do exist in the newsrooms and characterise them as aspirant journalists; attracted by the 'mirage' of this profession, which they tend to see in a romantic, quixotic light; but lacking the personality structure required to cope with the demands of this profession.

This 'mirage' of the profession is created by journalism schools and involves a set of expectations concerning the social status, professional prestige, material gains, and the public service ethics of a journalist. 'They come with grand expectations, they fall, most of them leave, some of them stay and do the job in order to survive', states one of the editors we interviewed. Editors and managers believe this mirage of the profession to be the main obstacle to the professionalization of aspirant journalists. This 
opinion is just an echo of a widespread idea in the Romanian society; that higher education is too theoretical and does not actually train students for their future profession, and that employers are forced to train recruits on the job. Moreover, because of this faulty professional training:

(...) there are no principled journalists with a backbone. Maybe they will be born in 10 or 20 years.

This apparent detachment of university training from the actual practice of journalism is an element associated with the first wave of democratisation, being the result of a multitude of approaches, understandings and philosophies of journalism (see Deuze 2005). In the practitioners view, in Romania this phenomenon is far from being a result of the post-communist transition. The constraints of the Communist regime made from the Romanian press a place where 'theory is theory, but practice is a different thing'.

One of the characteristics defining a liberal profession is the compulsory professional training in special validated study programs. Like elsewhere in the world, in Romania the profession of journalism is not characterised by this. We can even observe a growing tendency toward recruiting individuals whom did not graduate from a journalism school. This tendency is so strong that, in all our three cases, the respondents all worked in media organisations where few or no journalists were graduates of a journalism school. The recruitment criteria mentioned by editors and managers emphasize certain skills and knowledge (writing skills in Romanian, foreign language acquisition, general knowledge) and certain personality traits, like curiosity. Aspirant journalists also tend to agree that certain personal characteristics are more important than a journalism degree.

Due to the motives invoked above, editors and managers believe recruits without journalism degrees are more malleable and can be moulded to suit the objectives and constraints of the media organisations and, consequently, express clear preference towards them. Moreover, a partial explanation might be the fact that this type of candidates self-selects themselves through a combination of personal motivation and career expectations (Köcher 1986). We may also add a financial explanation: 
In this job you really do not make money. This is something many journalism graduates do not understand. There is a lot of work and very little money.

Within a media organisation, professionalization, as perceived by editors and managers, works like a control mechanism. How the owners and managers of a media organisation define professionalization is actually a mechanism of internal selection of journalists, based entirely on their adaptability to the specific context in which the media organisation operates.

From a sociological perspective, another defining element of a liberal profession is the existence of an ethical code and of a licensing system. The latter element can be found in the case of journalism in a strictly voluntary form, usually involving membership in professional associations as a means for symbolic legitimation. This symbolic legitimation does not seem necessary to the journalists in local news media organisations in Romania, probably due to the manner in which they perceive existing professional associations. All those interviewed point out that these organisations are cyclical, with high variations in terms of visibility and institutionalisation, which makes them unable to actually implement the ethical codes they adopt. Moreover, they are often representing strictly the interests of journalists working for national media organisations or are excessively personalised.

Even those who believe that professional organisations might contribute to professionalization never fail to point out a structural determinant of their weakness: the manner in which the relationship between media owners and journalists is defined limits any potential influence of the professional organisations. Consequently, professional associations are only able to contribute to professionalization within media organisations which are seen by their owners as strictly profit-oriented businesses. Another point agreed upon all by all the respondents is that ethical codes could be much more efficient if each media organisation formulated and implemented such a code.

From a highly subjective point of view, journalism is seen as a game. It can be interpreted using a strategic frame, because journalism is a profession which involves: 
(...) that you test all things required to be a newspaperman. From investigations, from revealing corruption to making, in plain Romanian, lobby for solving community problems.

This game, with all the associated specificity, urgency, and importance, is more important than 'that thing about being democracy's watchdogs, which is a formula way too old'. Journalism provides the opportunity to broaden one's horizon, to test oneself, to influence decisions, and, on top of everything, is thrilling.

\section{Clientelism and the 'political enlistment' of local media organisations}

Journalists and politicians tend to see the politics-journalism nexus in completely different terms (Brants et al. 2010; Schlesinger 2006). Differences are outlined by mutual criticism and occasional self-criticism, reflecting a reflexive insecurity concerning the role of both categories within a given society (Brants et al. 2010). How journalists position themselves in relationship with politics, including both how politics is defined and how journalists link with politicians, can vary within the same media system (Schudson 2007). In order to describe the complex relationship between local journalists, media organisations and political actors we use the notion of media-political clientelism (Hallin and Mancini 2004: 58-59), which describes a form of social and political organisation in which the access to public resources is controlled by powerful 'patrons' and provided to less powerful 'clients' in exchange for specific service.

The linkages between local politicians, journalists and media organisations in Romania are durable, even though, according to some of the people interviewed, there were some situations when media organisations have changed their political orientations rather abruptly. This durability is maintained on several levels. First, local media owners are either explicitly engaged into local politics or sympathize with certain local political organisations. Second, even though they are in none of the situations described above, local media owners may use the media organisation as an instrument to further their business objectives. In this case it is more probable that abrupt changes of political orientation will appear. Third, political actors may use soft censorship tools (denying access to information, 
exercising one's influence over public institutions in charge of controlling fiscal or competition related aspects of businesses) in order to secure the support of certain media organisations or coerce media organisations in avoiding some topics. Fourth, journalists, editors and media owners develop extra-professional relationships with local political actors. An interesting aspect of the media-politics clientelism is the extent to which we have voluntary or coercion situations (see Roudakova 2008). In Romania we identify both voluntary (extraprofessional relationships between journalists and politicians) and coercion aspects (soft censorship).

In this context media, owners are either 'patrons' or 'clients', depending on their degree of political engagement. The consequence is the instrumentalisation of media organisations to further the particular political and/or economic interests of the owners. Instrumentalisation affects local media organisations deeply in the sense that it does not allow them to fully commercialize. The local advertising market is limited, which gives an advantage to the local branches of national media organisations, and the biggest advertising clients on the market are public companies and local governments. An interesting aspect of the instrumentalisation of media organisations is their explicit transformation into electoral campaign instruments. Respondents make frequent reference to:

(...) owners who made newspapers for a specific goal. The goal disappeared, they lost the election, and consequently they closed the newspapers.

From the point of view of the respondents this is a situation which is completely unavoidable for local media organisations, their low profit margins making them attractive for investors with ulterior economic and political motives.

Media organisations are active actors in their own instrumentalisation. Some of the respondents mention that some media organisations are actively soliciting advertising contracts and other forms of financial incentives in order to avoid certain sensitive topics in their coverage of local political events. This is quite widespread:

(...) it happened in Iaşi, it happened in Cluj, it happened in Maramureş. I do not know where it did not happen.

This aspect is particularly important given that, during data collection the public prosecutors from Cluj-Napoca initiated the so-called Gazeta case. 
This was an investigation focusing on the owners and employees of a local media company accused of blackmailing politician and businessmen with the potential diffusion of seriously harming stories.

A label frequently used in Romania to describe the relationship between media organisations and political actors is 'political enlistment', rooted in the de facto situation of Romanian news media during the 1990s. The media were free, yet the state controlled a series of instruments allowing it to soft censor the media (the production and import of paper, printing and distribution facilities). The media swiftly divided itself into two categories: 'enlisted press', supporting the political regime, which was forced to accept compromises in order to survive, and 'the opposition press', backed by private financers. This situation has influenced deeply how political actors, media owners and journalists perceive their relationship. For example, local news media organisations are extremely sensitive to soft censorship exercised by local political actors. The respondents largely accept the notion that:

(...) we do not hit local authorities because they will no longer give us information.

Just how connected are local media and political elites is pointed out by the extraprofessional linkages between them. A young journalist describes an 'accord between journalists and political actors', which we interpret as a very clear reference to political clientelism. Another journalist emphasizes the potential consequences of such linkages and declares, in a very personal note, that:

(...) the fewest extraprofessional links with this world are desirable, so that you do not have any kind of obligations and servitudes toward the political world and the local administration.

This is very strong wording, which suggest that these linkages have serious influence over the professional relationship between local politicians and journalists. At the same time, the complex linkages between politicians (and other local elites) and journalists are connected to the perception of a similar social status and the perception of journalism as a profession that facilitates upward social mobility. In the words of a senior journalist: 
You are living the high-life. You are in a completely different world, very different from the miserable world in which we live in. You can talk with those people (...), and that puts you higher than others.

An interesting aspect is the dependency of the local relationships between media organisations and political actors on the national relevance of local political actors and processes:

(...) in [city name] you do not have such large scale politicians, so that it would matter when you hit them. Ours are sort of second league [our note, politicians].

The image of nationally relevant politicians is much more important and more closely linked to the extent to which local media organisations are either soft censored or directly instrumentalised.

\section{Truth, objectivity and the extraordinary in media practices}

'Simple values, such as truth, objectivity and common sense' are the essential values of journalism in Romania, being accepted as such by all the respondents, no matter the professional ideology they endorse. In practice the limits of truth are fluid, journalists and editors are constantly shaping them to fit the needs and interests of the media organisation. The means used to shape the truth resemble the categories of self-censorship: omission, dilution, change of emphasis, choosing certain rhetorical mechanisms; all of them anticipating either the receiving of a reward or the avoidance of sanctions (Lee and Lin 2006: 333). In local print media in Romania, articles criticising political and economic elites 'are not really known, unless they are published', because most of the time they do not get published. The sole exceptions are local news media which manage to maintain some economic independence:

If you lack the force and the money to move on your own, to care not of what your words demolish, then you shut up and build lies.

Self-censorship works in local news media and the journalists assume it as part of an informal addendum to their contract with the media organisation. From the point of view of some of our respondents, selfcensorship is institutionalised to such an extent that journalists prefer to transform themselves into bureaucrat-journalists: 
It is better to write ten trivial news pieces (our note, for which you get paid extra) than to write an investigation piece, because it won't be published.

In a less explicit manner, in the responses we received from part of our respondents, we identify a tension between 'the public's right to know' and the need to provide the audience with information that will attract attention and get audience members to continue to access the products of the respective media organisations. In the eyes of a young journalist, avoiding sensationalism works:

(...) to the detriment of the publication because, after all, readers seek the sensational. This is it, no matter if this is what they really want or what we educate them to want!

Like self-censorship, seeking the extraordinary does not necessary involves untruths, but it definitely involves interpreting the truth:

(...) these facts can change depending on the interests of those who have the power to change them. I believe we should not lie or distort the truth. But this does not seem possible anymore, you have to change if you want to attract the audience and make a news piece more interesting.

The interpretation of truth in order to emphasize extraordinary aspects is inherent to the profession and is part of the criteria for assessing the quality of journalistic products used by many media organisations. Sensationalism is thought to be less characteristic to the coverage of political and economic events, these being reflected using 'a classic blueprint'. Nevertheless, in these areas the reader 'is fooled' in a similar manner, with the emphasis on the ability to frame the story:

(...) in the end everything is true, yet it is put in a completely different perspective, completely different form.

The interpretation or packaging of truth, in the sense suggested by the respondents, involves selectivity in terms of people quoted (politicians, experts) and/or events and topics, selectivity towards one's judgement and the moral aspects of the profession, and selectivity in admitting the negative consequences of some media products. These are aspects that are very similar to what empirical research has identified in other countries (see Kepplinger and Köcher 1990). The main difference between Romanian journalists and their counterparts in other countries is that rather than the 
journalist's selectivity, this is selectivity institutionalised in the rules and routines of the media organisation.

Next to truth, objectivity is the most frequently mentioned value of a journalist. Nevertheless, it is poorly operationalized and remains a fuzzy concept. In the practice of journalism objectivity is frequently equalled with applying a set of professional rules and routines. Far from consensus, in Romania each media organisation defines its own set of rules and routines:

(...) each newspaper, each TV station has its own rules. To what extent these rules are, sort of speaking, deontological or not it's a different matter.

Some of the situations considered acceptable by most of the respondents show, in a comparative perspective, the persistence of loose rules and routines, which seriously affect the objectivity and quality of news. When they are not instrumentalised, Romanian local news media 'throw fishnets for politicians':

You are not sure of the facts or the names, you fish in troubled water. You write that ssome local leaders of the party $X$ > are involved in something and, depending on how they react, you uncover the truth.

The acceptability of these practices raises questions concerning news gathering procedures in the day-to-day operation of media organisations. Nevertheless, the notion of professional standards, even though they do not seem to actually work in practice, remains important due to their status as defence mechanisms (Kepplinger and Köcher 1990; Tuchman 1972). This state of fact is consistent with the observation that variations in defining professionalism are accompanied by variations in behaviour, derived from the journalists' convictions, attitudes and feelings (Esaiasson and Moring 1994).

Journalistic practice is constantly in conflict with the business logic of local news media organisations, fact reflected in both the opinions of journalists, on the one side, and editors and managers, on the other side. One of those interviewed expresses this conflict like this:

(...) you can write about anything you like, as long as this does not hurt the interests of the newspaper.

Effects are visible in terms of criteria for news selection, the separation between advertising and editorial content, balanced coverage, and on-the- 
job training for newcomers. Training does not include a clear depiction on acceptable news collection routines and emphasizes that:

(...) you must get what you must get! The means you use to obtain a piece of information are of no interest to anybody. When you come back from the field you have to have the information.

\section{Media freedom, diversity and pluralism}

In what follows, we focus on exploring how freedom of expression and media freedom, and the complementary notions of diversity and pluralism are conceptualised in the 'professional' ideology of Romanian journalists.

For the journalists interviewed as part of this project freedom of expression and media freedom are new, completely unfamiliar and requiring adaptation (journalists working since before 1989), or something taken for granted, nevertheless experimented in un imperfect form (younger journalists). Media freedom is dominantly being linked to media ownership and instrumentalisation issues: 'Media is not free! Because it is not rich'. The instrumentalisation of media organisations involves owners assuming superior rights to freedom of expression, derived from their property rights. Thus, local news media organisations become a tribune for the political opinions and economic interests of their owners. One respondent expresses her conviction that:

(...) some newspaper owners have ruined the press in (name of the city). They made us how we did not want to be.

From this resulted situations in which media freedom has been abused, with owners directly asking journalists to deliberately attack political opponents or business competitors. These situations became rarer as local politicians evolved:

Of course they are no longer so virulent. Journalists are no longer out there to bat for them as before. Now our political class is a bit more subtle. They learned that you can whip someone smiling, that you can threaten someone with a wide smile.

When media owners choose not to abuse media freedom and regard their investment in a media organisation as simply business, they usually 
choose to fine-tune content toward entertainment and trivial information. A journalist tell us that:

We do not go to the press conferences of local political parties. This is the owner's requirement; he doesn't belong to either party.

We have an obvious detachment from the democratic function of the mass media; not approaching political events and issues equals not exercising the role of the media as derived from mistrust in government and politicians.

Very much like media owners, journalists tend not to differentiate between their freedom of expression as citizens and media freedom, which is associated with a set of social and political responsibilities. Opinion journalism occupies an important place in Romania. We may associate this fact with an understanding of media freedom specific to post-communism, emphasizing more the right of the journalists to express her or his opinion than the right of the audience to be informed (Voltmer 2000: 494). The audience/the citizenry are rarely mentioned by journalists when asked to define their role in society. This role definition happens exclusively taking into account the journalist's relationship with political actors, media owners, and other journalists. Citizens are nothing but a passive audience provided with information and entertainment. Accountability to this audience is reduced to market mechanisms, journalists have 'to write well' so that people will read them and the media organisation will survive. When discussing media freedom and the instrumentalisation of media organisations, journalists and editors take a personal tone. They frame this in terms of curbing their right to write about anything they like, to write 'a journalistic investigation for one's prestige' rather than in term of curbing the citizens' right to know and to be protected from abuse of power. Similarly with journalists in other countries (see Algarra and Gaitano 2011), Romanian journalists seem incapable of distinguishing between their role in the political system as journalists and their role as citizens. They see their position as a means to use the freedom of expression citizenship rights.

Journalistic independence is a catchphrase, despite admissions of selfcensorship, soft censorship and inappropriate linkages between editorial policy and the political and economic interests of the owner. In the view of our respondents, this independence can be secured either through the legislative protection of journalists or through trade-unionisation. The 
emphasis on the responsibilities associated with media freedom appears strictly in the case of those practicing journalism as a temporary occupation. A perceived lack of responsibility among journalists is frequently being cited as a reason for choosing a different profession.

We have an external pluralism, secured through the different political orientations of media owners. None of our respondents provided us with information that would indicate the existence of at least a limited internal pluralism. The access to this profession comes to an ex ante endorsement of the political orientation of a media organisation, including the notion that this political orientation may change radically if the interests of the owner require it. The plurality of voices and opinions is strictly dependent on a series of inter-related economic and political factors exogenous to media organisations.

When referring to the notion of diversity, journalists and editors tend to reduce it to the matter of how many channels for information are available and frame it as a partial solution to the problem of media instrumentalisation:

Media diversity, or the more they are... When a journalist is stopped from publishing an investigation, it may be published elsewhere. This happily remedies the situation.

Diversity is never equalled with aspects such as reflecting the demographic differences in society or providing a wide variety of alternatives in terms of programming, all invoked in other countries in operationalizing diversity (Aslama, Hellman and Sauri 2004).

\section{Conclusion}

In the context of the debate on convergence in the professionalization of journalism it is widely accepted that the key elements in an internationalised model of journalistic professionalism are freedom of expression and independence (Josephi 2007). In this direction, this article has approached the professionalization of journalism in Romania and its associated 'ideology'. Like in many other countries, journalism in Romania is a form of expression that overshadows all others. The professionalization of journalism is mainly based on symbolic criteria such as the role of the 
journalist within society and the political system. Two professional 'ideologies' are distinguishable within Romanian news media organisations, describable by resorting to the objectivist tradition of American and British journalism and the European continental tradition of journalism. At the same time, we identify a tendency towards transforming journalism into a mere occupation, partially explainable due to the precarious finances of the media organisations and the instrumentalisation of media organisations by their owners. The norms, rules, and procedures usually associated with professional journalism in Western societies are mentioned by Romanian journalists, but they are employed only superficially in day-to-day activity. This professionalization of media built on symbolic elements related to the social and political role of journalists is extremely important in the process of accommodation to the instrumentalisation of media organizations by their owners. Within media organisations a freedom v. order dilemma is visible, with order usually operationalized having in view the instrumental purposes of the organisation (stemming from the commercial nature of the organisation and the interests of the owners) rather than the normative goals (stemming from the common good nature of information and the sociopolitical role attributed to media organisations). The professionalization of journalism in Romania is under the double threat posed by instrumentalisation and commercialisation. This finding is consistent with research on Western media systems, showing that economic pressures on media organisations and commercialisation influence significantly journalistic practices, professional autonomy, professional values, and the quality of political journalism (Plasser 2005).

The relationships between journalists and media organisations, on the one hand, and political actors, on the other hand, can best be described as a mix of desirable professional autonomy, based upon a significant dose of adversity between journalists and politicians, and a de facto acceptance of dependency in this relationship, going beyond what is considered acceptable from both a democratic theoretical and practical point of view. Professional autonomy is part of an idealised view on journalism and its role within the political system, involving a black and white description of the relationships between politicians and journalists in terms of total independence and dependence, and ignoring the shades of grey present in 
day-to-day interactions. From a citizens' point of view, as long as the instrumentalisation of media organisations remains widespread, the situations in which the media organisations acknowledge the political partisanship resulting from this instrumentalisation would be rather positive. The media - political parallelism might be far off the normative expectations of a free press, nevertheless, as long as all opinions are reflected and the citizens-readers are warned about the political views pursued by the media organisations, it is not necessarily working against democracy.

Probably the most important result from this analysis points out the fact that journalists do not seem to make the necessary distinction between their free speech as citizens and their free speech as journalists, the latter associated with some normative expectations of responsibility in exercising media power. To this we add the fact that media owners seem to assume they have greater speech rights than the rest of the citizens, as they use the media organisations to pursue their political and business goals. This aspect falls within a broader discussion about wealth-based speech.

\section{Acknowledgements}

An earlier version of this paper was presented at the Political ideologies, values and behaviours International Conference, at the University of the West of Timişoara, December 8-9, 2006. The author wishes to thank the participants at the conference for their suggestions and comments. The paper is the result of the Mass media and politics in Romania: political control and political culture research project, funded through the CNCSIS Td_15/66 (2004-2006) research grant, project director Cristina Stănuş.

\section{References}

Algarra, Manuel Martin and Norberto Gonzalez Gaitano. 2011. The Political Role of the Spanish Journalist. Political Communication 14 (4): 481-495. Aslama, Minna, Heikki Hellman and Tuomo Sauri. 2004. Does Market-Entry Regulation Matter?: Competition in Television Broadcasting and Programme Diversity in Finland, 1993-2002. Gazette 66 (2): 113-132.

Barendt, Eric. 2007. Fredom of Speech. Oxford: Oxford University Press.

Benson, Rodney and Daniel C. Hallin. 2007. How States, Markets and Globalization Shape the News. European Journal of Communication 22 (1): 27-48. 
Blumler, Jay G. and Gurevitch, Michael. 1995. The crisis of public communication. Londra: Routledge.

Bot, Mălin. 2004. Ziarişti amenințați, ziarişti bătuți. Bucureşti: Humanitas.

Brants, Kees, Claes de Vreese, Judith Moller and Philip van Praag. 2010. The Real Spiral of Cynicism? Symbiosis and Mistrust between Politicians and Journalists. International Journal of Press/Politics 15 (1): 25-40.

Broddason, Thorbjörn. 1994. The Sacred Side of Professional Journalism. European Journal of Communication 9 (3): 227-248.

Cohen, Elliot D., ed. 1992. Philosophical Issues in Journalism. New York: Oxford University Press.

Deuze, Mark. 2005. What is journalism? Journalism 6 (4): 442-464.

Donsbach, Wolfgang and Thomas E. Patterson. 2004. Political News Journalists: Partisanship, Professionalism, and Political Roles in Five Countries. In Comparing Political Communication: Theories, Cases, and Challenges, eds. Frank Esser and Barbara Pfetsch, 251-270. Cambridge: Cambridge University Press.

Esaiasson, Peter and Tom Moring. 1994. Codes of Professionalism: Journalists Versus Politicians in Finland and Sweden. European Journal of Communication 9 (3): 271-289.

Graber, Doris A. 1997. Mass media and American politics. Washington, D.C.: CQ Press.

Hallin, Daniel C. and Paolo Mancini. 2004. Comparing media systems: three models of media and politics. Cambridge: Cambridge University Press.

Heikkilä, Heikki and Rist Kunelius. 2006. Journalists Imagining the European Public Sphere: Professional Discourses about the EU News Practices in Ten Countries. Javnost - The Public 13 (4): 63-80, http:/ / www.javnost-thepublic.org/article/2006/4/4/

Josephi, Beate. 2007. Internationalizing the journalistic professional model: imperatives and impediments. Global Media and Communication 3 (3): 300-306.

Kepplinger, Hans Mathias and Renate Köcher. 1990. Professionalism in the Media World? European Journal of Communication 5 (2): 285-311.

Köcher, Renate. 1986. Bloodhounds or Missionaries: Role Definitions of German and British Journalists. European Journal of Communication 1 (1): 43-64.

Lee, Francis L.F. and Angel M.Y. Lin. 2006. Newspaper editorial discourse and the politics of self-censorship in Hong Kong. Discourse E Society 17 (3): $331-358$.

McQuail, Dennis. 2010. McQuail's Mass Communication Theory. London: Sage Publications.

Pasti, Svetlana. 2005. Two Generations of Contemporary Russian Journalists. European Journal of Communication 20 (1): 89-115.

Plasser, Fritz. 2005. From Hard to Soft News Standards? The Harvard International Journal of Press/Politics 10 (2): 47-68. 
Roudakova, Natalia. 2008. Media-political clientelism: lessons from anthropology. Media, Culture \& Society 30 (1): 41-59.

Ruusunoksa, Laura. 2006. Public Journalism and Professional Culture: Local, Regional and National Public Spheres as Contexts of Professionalism. Javnost - The Public 13 (4): 81-98, http://www.javnost-thepublic. org/article/2006/4/5/

Schlesinger, Philip. 2006. Is there a crisis in British journalism? Media, Culture $\mathcal{E}$ Society 28 (2): 299-307.

Schudson, Michael. 2007. The Concept of Politics in Contemporary U.S. Journalism. Political Communication 24 (2): 131-142.

Singer, Jane B. 2003 . Who are these Guys? Journalism 4 (2): 139-163.

Tuchman, Gaye. 1972. Objectivity as Strategic Ritual: An Examination of Newsmen's Notions of Objectivity. American Journal of Sociology 77 (4): 660-679.

Tumber, Howard. 2006. Journalists at Work - Revisited. Javnost - The Public 13 (3): 57-68, http:/ / www.javnost-thepublic.org/article/2006/3/5/

Voltmer, Katrin. 2000. Constructing Political Reality in Russia. European Journal of Communication 15 (4): 469-500. 